\title{
Diet composition of the Korean wild boar Sus scrofa coreanus (Suidae) at Mt. Jeombongsan, Korea
}

\author{
Hyung-Min Shin ${ }^{1}$, Jihee Kim', Seon Deok Jin², Ho-Yeon Won² and Sangkyu Park ${ }^{1 *}$ (D)
}

\begin{abstract}
Background: Korean wild boars (Sus scrofa coreanus Heude), because of their adaptability, are a widespread large mammal; however, they sometimes cause problems by invading farms and eating the crops, creating insufficiencies of some foods in South Korea. To understand the diet composition of Korean wild boars according to sex and body size, we collected their feces from Mt. Jeombongsan, Seoraksan National Park, South Korea. The sizes of fecal samples were measured, and genomic DNA was extracted from the samples. We amplified specific loci targeting plants (rbcL and $t r n L)$ and animals (COI) to detect the food sources of this omnivore and amplified the ZF and SRY regions to determine the sex.

Results: In the wild boar feces, Rosaceae and Bryophyte were the most frequently detected plant food sources at the family level and Diptera and Haplotaxida were the most frequently detected animal food sources at the order level. As a result of sex determination, the sex ratio of wild boars collected in the Mt. Jeombongsan area was approximately 1:1. Our result suggested that there is no significant difference between the diet composition of male and female boars. Based on the average cross-sectional area of the feces, the top 25\% were classified into the large body size group and the bottom $25 \%$ were classified into the small body size group. The large body size group mainly preferred Actinidiaceae, and the small body size group most frequently consumed Fagaceae. The diet of the large body size group was more diverse than the small body size group.

Conclusions: Our results showed that the wild boars preferred Rosaceae, especially Sanguisorba and Filipendula, as plant food sources, and Diptera and Coleoptera of Insecta as animal food sources. Based on the results, the dietary preferences of wild boar appear to be distinguished by not their sex but their body size. Our study could help to elucidate the feeding ecology and population structure of wild boar, as well as address conservation and management issues.
\end{abstract}

Keywords: Sus scrofa, Mt. Jeombongsan, Feces, Diet, Sex determination

\section{Background}

Korean wild boars (Sus scrofa coreanus Heude) are a widespread large mammal because of their ability to survive well in changing environments. However, the recent destruction of their habitats and food shortages have caused them to invade private houses and root up

\footnotetext{
*Correspondence: daphnia@ajou.ac.kr

'Department of Biological Science, Ajou University, Suwon 16499, Republic of Korea

Full list of author information is available at the end of the article
}

farmlands, which is a cause of great concern in South Korea (Calenge et al. 2004; Herrero et al. 2006; Wirthner et al. 2012).

According to previous studies, the diet of wild boar can be variable, depending on the accessible food sources (Herrero et al. 2006). They are generally known as omnivores that mainly eat plants, but some researchers have reported them engaging in predation or active hunting (Wilcox and Vuren 2009; Wishart et al. 2015). Wild boars have various diet habits and food

(c) The Author(s). 2020 Open Access This article is licensed under a Creative Commons Attribution 4.0 International License, which permits use, sharing, adaptation, distribution and reproduction in any medium or format, as long as you give appropriate credit to the original author(s) and the source, provide a link to the Creative Commons licence, and indicate if changes were made. The images or other third party material in this article are included in the article's Creative Commons licence, unless indicated otherwise in a credit line to the material. If material is not included in the article's Creative Commons licence and your intended use is not permitted by statutory regulation or exceeds the permitted use, you will need to obtain permission directly from the copyright holder. To view a copy of this licence, visit http://creativecommons.org/licenses/by/4.0/. 
preferences depending on their habitat type, and take different trophic functions and play roles in various environments (Ballari et al. 2015).

In South Korea, there are limited basic data available on wild boar and little understanding of their ecological roles and interactions in nature (Lee and Lee 2014). Particularly, there is a lack of basic data on the food habits and ecological niche of wild boar (Choi et al. 2006). Wild boars are an important link species between top predators and plants. Therefore, it is highly important to have basic scientific data, such as the food sources and population structure, for the management of wild boars. We hypothesized that their diet compositions might be variable depending on their sex and body size. Because wild animals-especially elusive animals-are hard to observe in the field, non-invasive methods are becoming increasingly popular (Valentini et al. 2008). A previous study comparing the efficiencies of traditional methods of direct dissection and DNA barcoding technology reported that the DNA barcoding method gave by far more taxonomically detailed results than did the traditional one (Soininen et al. 2009). Direct dissection can give biased results because of unidentified matters, while using DNA barcoding technology can lead to the fine resolution of dietary variation, detecting rare food items with small amounts of target DNA. We used noninvasive molecular analysis on the feces of wild boars to study their diet compositions and sex ratio.

The male to female ratio is important information for any population. This ratio simply shows the current ratios of males and females, but can also be used as a measure of the future potential of the group. The social sex ratio can be used to predict the future growth potential of the population (Skogland 1986; Han et al. 2011). Han et al. (2011) reported that the proportion of females on Jeju Island, South Korea, is twice that of males, and the population was predicted to have a constant potential to increase. This ratio can be used for predicting the future growth potential of the wild boar population. Wilcox and Vuren (2009) reported that it is important for females to consume vertebrates for the physiological costs of reproduction. Protein deficiency due to breeding can be one factor that causes females to consume food selectively. In addition, differences in body size as well as sex can be attributed to differences in plant food sources (Wishart et al. 2015). Wishart et al. (2015) reported that adults forage a lot of grasses and crop materials compared to juveniles. In contrast, juveniles tend to consume more forbs that are easier to digest. Sex and age can be factors influencing the diet compositions of wild boars.

Information on the favorite foods and dietary habits of wild boars can be used to regress or attract wild boars in South Korea. It can also be used as basic information for maintaining a suitable population density through the identification of population structure. Non-invasive methods of fecal sampling without artificial hunting or interference are environmentally friendly research methods that can be conducted without destroying natural ecosystems. This study could provide a general direction and method of studying the diet and feeding habits of wild animals beyond wild boars. This approach for analyzing diet compositions via non-invasive methods, especially using fecal samples, can be adapted to other wild animals and ecosystems.

This study aimed to investigate the overall diet composition of wild boars and its possible influencing factors. We attempted to reveal the diet composition of wild boars as omnivores and how they were influenced by sex and body size. We used non-invasive molecular analysis, such as DNA barcoding, on the fecal samples of wild boars collected from the Mt. Jeombongsan area, in Seoraksan National Park, South Korea.

\section{Methods \\ Sample collection}

This study was performed in the Mt. Jeombongsan area, in Seoraksan National Park, Gangwon-do, in South Korea ( $38^{\circ} 02^{\prime} 57.7^{\prime \prime} \mathrm{N} 128^{\circ} 25^{\prime} 31.0^{\prime \prime}$ E) (Fig. 1). This area has been denominated as the first biosphere reserve in South Korea by UNESCO. Therefore, this mountainous area is protected by the government and access is only available to permitted people. Based on previous research and observations, there are a diversity of plants, including endemic plants. KNPRI (2012) reports that this area supports 44 orders, 108 families, 404 genera, 676 species, 1 subspecies, 100 varieties, and 13 forms of a total of 790 taxonomic groups of vascular plants.

We collected wild boar fecal samples from the Mt. Jeombongsan area once per month from June 2016 to June 2018. Based on previous observations, we climbed a trail course which was a known habitat of wild boar as well as a regular mountaineering road to collect more fecal samples. After non-invasively collecting wild boar fecal samples, the feces were first identified by their forms and odors. Collected samples were recorded in order and kept in a frozen state in small zipper bags until they were delivered to the laboratory. They were stored in a deep freezer at $-80{ }^{\circ} \mathrm{C}$ until genomic DNA extraction.

\section{Measurement of fecal sample sizes}

The shapes of wild boar feces were not atypical, and their amounts varied depending on their nutritional statuses. Since fecal samples cannot be larger than the size of the anus, we assumed that the maximum size of the feces would be the size of the anus. The longest length was set to a major axis in a cross-section of the feces, 


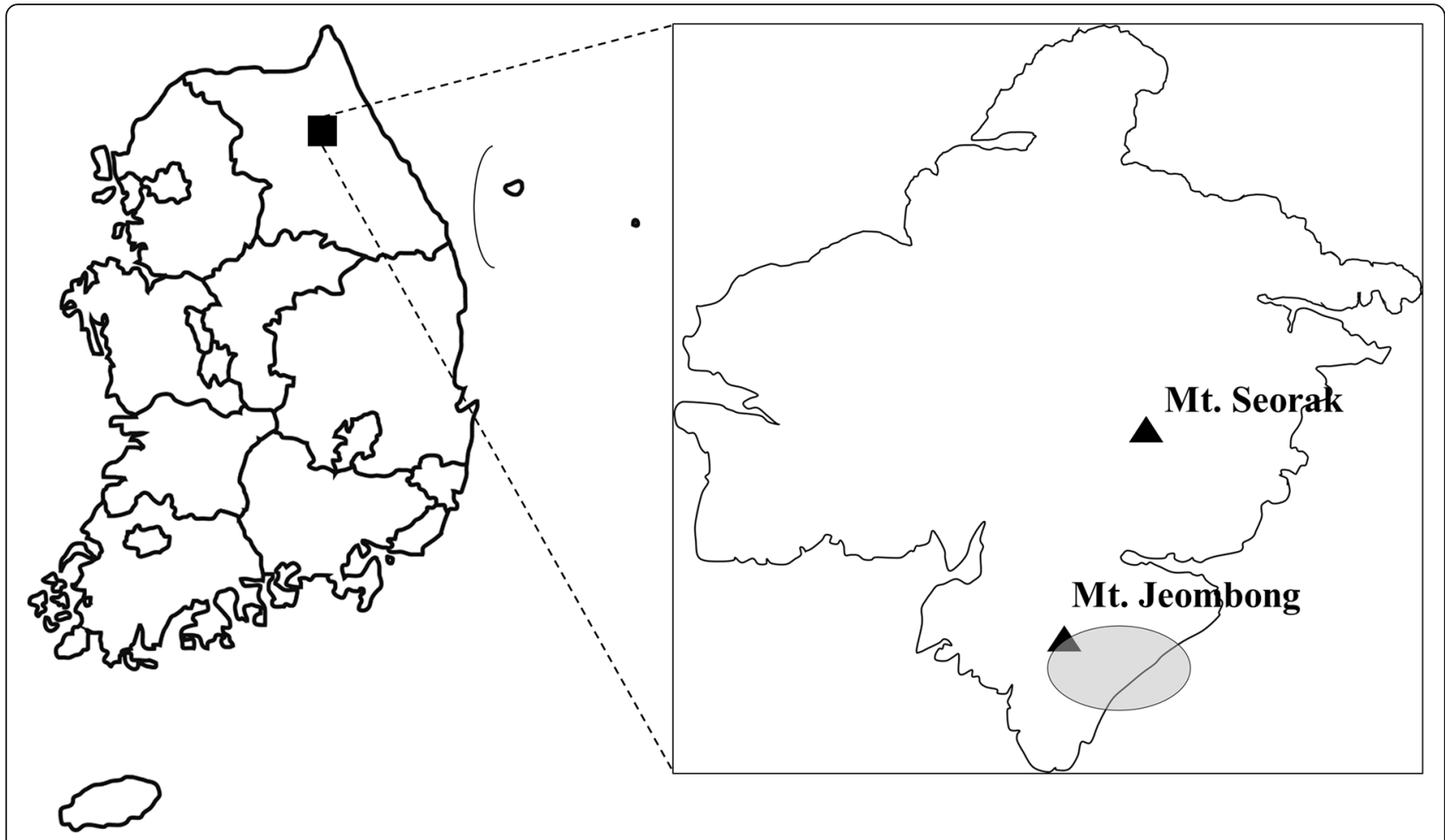

Fig. 1 Location of at Mt. Jeombongsan in Seoraksan National Park, South Korea. Sampling site was marked with dark circle

and a perpendicular length to the major axis was regarded as a minor axis. We measured the diameter of the feces with Vernier calipers (Morden et al. 2011). Since animals tend to grow larger as they get older, this leads to an increased anus size. Based on the crosssectional areas of the feces, wild boars were grouped into large and small size classifications. Based on the average cross-sectional areas, the top $25 \%$ were classified as the large body size group and the bottom $25 \%$ were classified as the small body size group to exclude ambiguous ones in the middle.

\section{DNA extraction}

We extracted genomic DNA from wild boar fecal samples using the QIAamp DNA Stool Mini kit (Qiagen, Hilden, Germany) following the kit manufacturer's protocols except for the lysis step. For the complete homogenization of samples, two 5-mm stainless steel beads were added to the sample for the lysis step, which was then shaken by a ball mill (Retsch, Haan, Germany). Extracted DNA and diluents were retained in a deep freezer at $-80{ }^{\circ} \mathrm{C}$ until further experiment.

\section{Dietary analysis}

All DNA amplifications were carried out in a final volume of $20 \mu \mathrm{l}$, using $1 \mu \mathrm{l}$ of DNA extract as a template. The amplification mixture contained $1 \mathrm{U}$ of FastMix/Frenche ${ }^{\text {tx }}$
PCR (i-StarTaq) premix (iNtRON, Seongnam, Korea) and $0.25 \mu \mathrm{M}$ of each primer. For plant food sources, we selected two primer sets especially targeting chloroplasts (Table 1).rbcL_S1_For and rbcL_S1_Rev were used to amplify the ribulose-1,5-bisphosphate carboxylase/oxygenase large subunit $(\mathrm{rbcL})$ gene (Kress and Erickson 2007). In addition, trnL_g and trnL_h were used to amplify the trnL (UAA)-P6 loop for detailed resolution (Taberlet et al. 2007). PCR was performed in a thermal cycler (Applied Biosystems, Foster City, USA) and PTC-200 (MJ Research, Watertown, MA, USA) under the following conditions: initial denaturation for $8 \mathrm{~min}$ at $94{ }^{\circ} \mathrm{C}, 40 \mathrm{cy}$ cles of denaturation at $94{ }^{\circ} \mathrm{C}$ for $20 \mathrm{~s}$; annealing at $54{ }^{\circ} \mathrm{C}$ for $15 \mathrm{~s}$; and extension at $72{ }^{\circ} \mathrm{C}$ for $45 \mathrm{~s}$, and a final extension at $72{ }^{\circ} \mathrm{C}$ for $5 \mathrm{~min}$. For animal food sources, MICOlintF (Leray et al. 2013) and PolyShortCoiR (Carr et al. 2011) were used to amplify mitochondrial-encoded cytochrome oxidase subunit I (COI). Since DNA extracted from fecal samples are usually dominated by host templates, we need to inhibit the amplification of wild boar DNA mixed with another DNA. In this study, we used a blocking oligonucleotide developed for the blocking of host templates and improved to detect prey (Robeson et al. 2018; Vestheim and Jarman 2008). The PCR mixture was denatured at $95{ }^{\circ} \mathrm{C}$ for $4 \mathrm{~min}$, followed by 50 cycles of $30 \mathrm{~s}$ at $95^{\circ} \mathrm{C}, 30 \mathrm{~s}$ at $55^{\circ} \mathrm{C}, 30 \mathrm{~s}$ at $72{ }^{\circ} \mathrm{C}$, and a final extension at $72^{\circ} \mathrm{C}$ for $5 \mathrm{~min}$. 
Table 1 Information on primer sets used for dietary analysis of Sus scrofa

\begin{tabular}{|c|c|c|c|}
\hline Primer & Target region & Sequence $\left(5^{\prime}-3^{\prime}\right)$ & Reference \\
\hline $12 \mathrm{SV} 5 \mathrm{~F}$ & \multirow{2}{*}{$\begin{array}{l}12 \mathrm{~s} \text { ribosomal unit } \\
\text { (vertebrate) }\end{array}$} & TAGAACAGGCTCCTCTAG & \multirow[t]{2}{*}{ Riaz et al. 2011} \\
\hline $12 \mathrm{SV} 5 \mathrm{R}$ & & TTAGATACCCCACTATGC & \\
\hline $\operatorname{trn} \mathrm{L} \_g$ & \multirow[t]{2}{*}{ trnL-P6loop (plant) } & GGGCAATCCTGAGCCAA & \multirow[t]{2}{*}{ Taberlet et al. 2007} \\
\hline $\operatorname{trnL} \mathrm{h}$ & & CCATTGAGTCTCTGCACCTATC & \\
\hline rbcL_S1_For & \multirow[t]{2}{*}{ rbcL (plant) } & ATGTCACCACAAACAGAGACTAAAGC & \multirow{2}{*}{$\begin{array}{l}\text { Kress and Erickson } \\
2007\end{array}$} \\
\hline rbcL_S1_Rev & & GTAAAATCAAGTCCACCRCG & \\
\hline MICOlinF & \multirow[t]{2}{*}{ COI (animal) } & ATGTCACCACAAACAGAGACTAAAGC & Leray et al. 2013 \\
\hline PolyShorCoiR & & GTAAAATCAAGTCCACCRCG & Carr et al. 2011 \\
\hline Pig_BLK & COI region of Sus scrofa & $\begin{array}{l}\text { ACCCACCTTTAGCTGGAAACTTAGCCCATGCAGGAGCTTCAGTTGATCTAACAA\| } \\
\text { ॥CTCCCTACACCT }\end{array}$ & Robeson et al. 2018 \\
\hline
\end{tabular}

The PCR products were purified using an AccuPrep ${ }^{\circ}$ PCR purification kit (Bioneer K-3034, Korea). Purified products were inserted into the $\mathrm{pGEM}^{\circ}-\mathrm{T}$ Easy Vector (Promega, USA) according to the manufacturer's protocols and were transformed into DH5 $\alpha$ chemically competent cells. The cells were plated in Luria-Bertani agar plus ampicillin medium with $2 \% \mathrm{X}$-gal (w/v) solution to facilitate antibiotic selection and blue-white screening. After the cloning step, about four positive clones per sample were selected and amplified using the M13F and M13R primer pair. PCR was performed under the following conditions: initial denaturation for $10 \mathrm{~min}$ at 95 ${ }^{\circ} \mathrm{C}$; followed by 35 cycles at $94{ }^{\circ} \mathrm{C}$ for $30 \mathrm{~s}, 55^{\circ} \mathrm{C}$ for $30 \mathrm{~s}$, and $72{ }^{\circ} \mathrm{C}$ for $1 \mathrm{~min}$; and a final extension at $72{ }^{\circ} \mathrm{C}$ for 7 min. Sequencing was conducted by a commercial sequencing service company (Genotech, Korea). Each obtained sequence was identified through BLASTN analysis using the GenBank database.

\section{Sex determination}

Sex chromosomes $\mathrm{X}$ and $\mathrm{Y}$ in mammals cause differences between males and females. The SRY gene located on the mammalian $\mathrm{Y}$ chromosome plays an important role in male development. The $\mathrm{ZF}$ gene is one of the most common binding motifs in mammals. The $\mathrm{X}$ linked ZFX and Y-linked ZFY are homologous, but there is some difference in length due to insertion. In SRY PCR, we can observe one band only in male samples. In female samples, no band can be observed, and therefore, the reliability of the results is poor. Therefore, amplification of ZF gene was also conducted to complement that result. DNA extracted from male and female tissues were used as positive controls.

Pre-extracted DNA from the feces of wild boar were used for determining sex. We selected specific primer sets amplifying the $S R Y$ and $Z F$ genes (Table 2). PCR was carried out in a $20-\mu \mathrm{l}$ final reaction volume containing $1 \mathrm{U}$ of FastMix/Frenche ${ }^{\text {Tm }}$ PCR (i-StarTaq) premix (iNtRON, Seongnam, Korea) and $0.25 \mu \mathrm{M}$ of each primer. PCR was performed in a thermal cycler (Applied Biosystems, Foster City, CA, USA) and PTC-200 (MJ Research, Watertown, MA, USA). For SRY amplification, the condition was as follows: initial denaturation for 5 min at $94{ }^{\circ} \mathrm{C}, 50$ cycles of denaturation at $94{ }^{\circ} \mathrm{C}$ for $30 \mathrm{~s}$; annealing at $58{ }^{\circ} \mathrm{C}$ for $50 \mathrm{~s}$; extension at $72{ }^{\circ} \mathrm{C}$ for $50 \mathrm{~s}$; and a final extension at $72{ }^{\circ} \mathrm{C}$ for $5 \mathrm{~min}$. For $Z F$ amplification, the condition was as follows: initial denaturation for $5 \mathrm{~min}$ at $94{ }^{\circ} \mathrm{C}$, five cycles of denaturation at $94{ }^{\circ} \mathrm{C}$ for $45 \mathrm{~s}$; annealing at $58{ }^{\circ} \mathrm{C}$ for $1 \mathrm{~min}$; extension at $72{ }^{\circ} \mathrm{C}$ for $1 \mathrm{~min}, 50$ cycles of denaturation at $94{ }^{\circ} \mathrm{C}$ for $45 \mathrm{~s}$; annealing at $57{ }^{\circ} \mathrm{C}$ for $1 \mathrm{~min}$; extension at $72{ }^{\circ} \mathrm{C}$ for $1 \mathrm{~min}$; and a final extension at $72{ }^{\circ} \mathrm{C}$ for $5 \mathrm{~min}$. For the reliability of the results, DNA extracted from the tissue of both sexes were used as positive controls. After the PCR step, the reaction products confirmed the pattern of the target band through electrophoresis. In the SRY PCR response, one target band was observed at $704 \mathrm{bp}$ for males but not for females. In the ZF PCR response, two target bands were observed at $379 \mathrm{bp}$ and $476 \mathrm{bp}$ for males, but only one was observed at $379 \mathrm{bp}$ for females.

Table 2 Information on primer sets used for sex determination of Sus scrofa coreanus

\begin{tabular}{llll}
\hline Primer & Target region & Sequence $\left(5^{\prime}-3^{\prime}\right)$ & Reference \\
\hline pSRYF & SRY & CCCTTTTCAAATGGTGCAGT & Cho et al. 2005 \\
pSRYR & & TGTGAGAAAGTCCCGGCTGT & \\
PZFXYF & ZF & GCTGACCCTGGAGAAGATGA & \\
pZFXYr & & CTTCTTGTTGAGAGTCATTGACAG & \\
\hline
\end{tabular}




\section{Results}

\section{Food sources of wild boars}

During the entire study period, genetic information was obtained from 79 of 80 fecal samples. We categorized food sources as either plant or animal sources and analyzed them accordingly. Finally, 188 clones were detected as plant food sources and 119 as animal food sources. Of the 307 total clones from diet compositions, plant food sources accounted for $61 \%$ and animals for $39 \%$. It was difficult to perform accurate quantification between clones of plant and animal food sources, because the same primers were not used for amplification in this study. However, since a sufficient number of clones were analyzed, the relative ratio between plants and animals could be used for comparison. Wild boars appeared to be more dependent on plants than animals for food. Of the 80 total fecal samples collected for this study, 79 samples were successfully amplified in the rbcL and trnL regions, and 188 clones of plants were detected, disregarding duplicates (Fig. 2). A total of 27 families of 18 orders of plants were detected as plant food sources. During the entire study period, a diverse array of plants was detected as plant food sources. The top 3 families, Rosaceae, Bryophyte, and Fagaceae, accounted for more than half of the total detected. The most frequently detected plant food sources were plants from Rosaceae, accounting for 22\%; Sanguisorba,
Filipendula, and Prunus were the most frequently detected genera in Rosaceae. The next most detected plant food source was bryophytes, commonly known as mosses. They could not be analyzed at a high resolution due to their low identity, owing to insufficient prior genetic information registered on the NCBI database. Fagaceae and Actinidiaceae plants were also detected as major plant food sources for wild boars. Quercus were always detected at a high rate regardless of the season. Acorn, the fruit of the Quercus, is known to be a main plant food source for wild boars. The Actinidiaceae family included the only one genus, Actinidia, which was the most frequently detected genus. It was notable that some detected plants, such as Apiaceae, have known medicinal uses. Although Araceae is known for its toxicity, it was detected several times. In both 2016 and 2017, the number of samples in summer was the highest among the four seasons (data not shown). We compared plant food sources between 2016 and 2017, especially in the summer period (Fig. 3). The overall dominance of Rosaceae, Bryophyta, and Fagaceae was similar in 2016 and 2017. However, the proportion of Rosaceae in 2017 was especially high. We collected a large amount of wild boar feces from one specific place, where the group appeared to have fed on Rosaceae, especially Sanguisorba. In 2016, there were dispersive samplings in many places, in which a variety of food sources were detected.

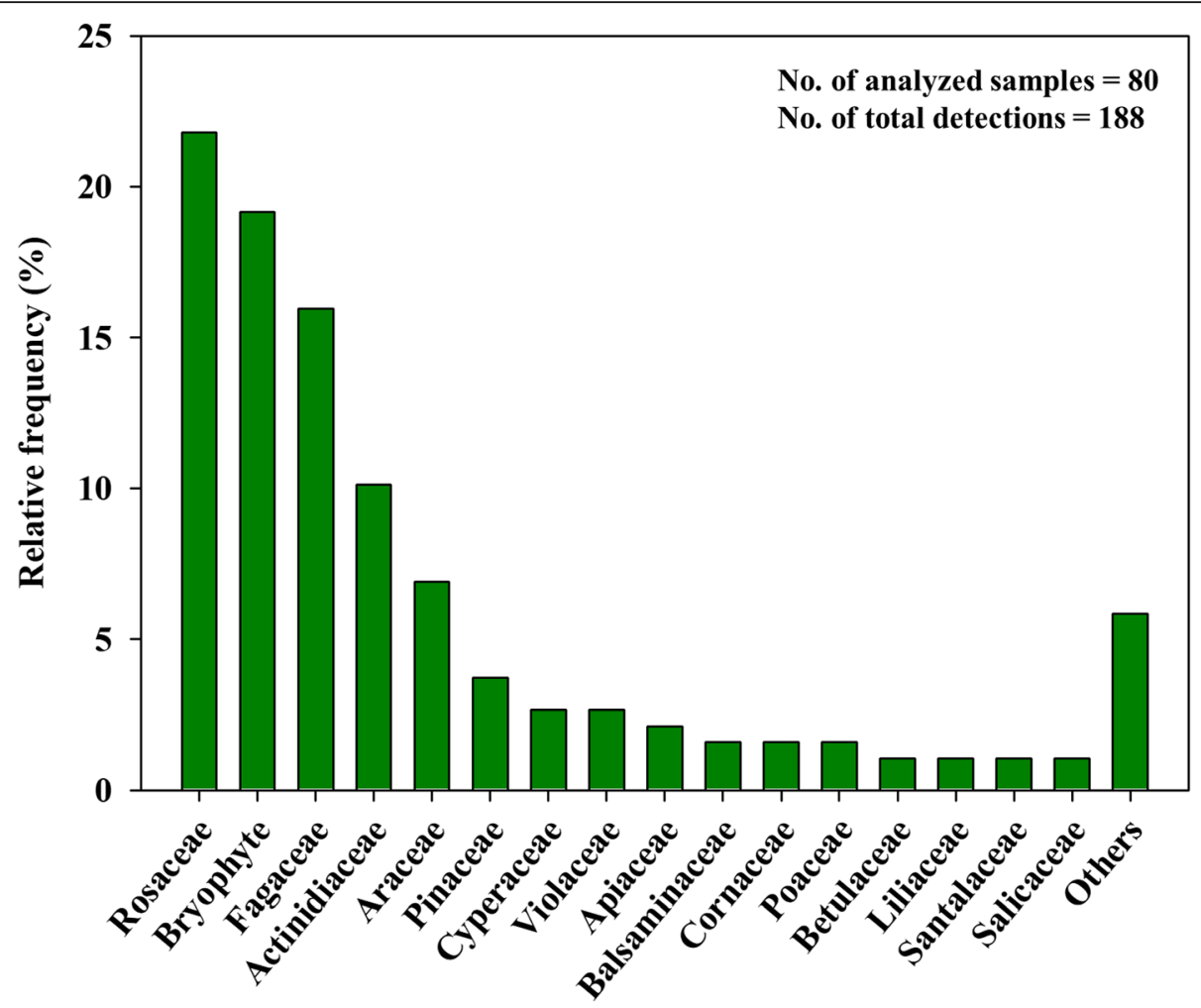

Fig. 2 The percentage of detected plant food sources identified to the family level 

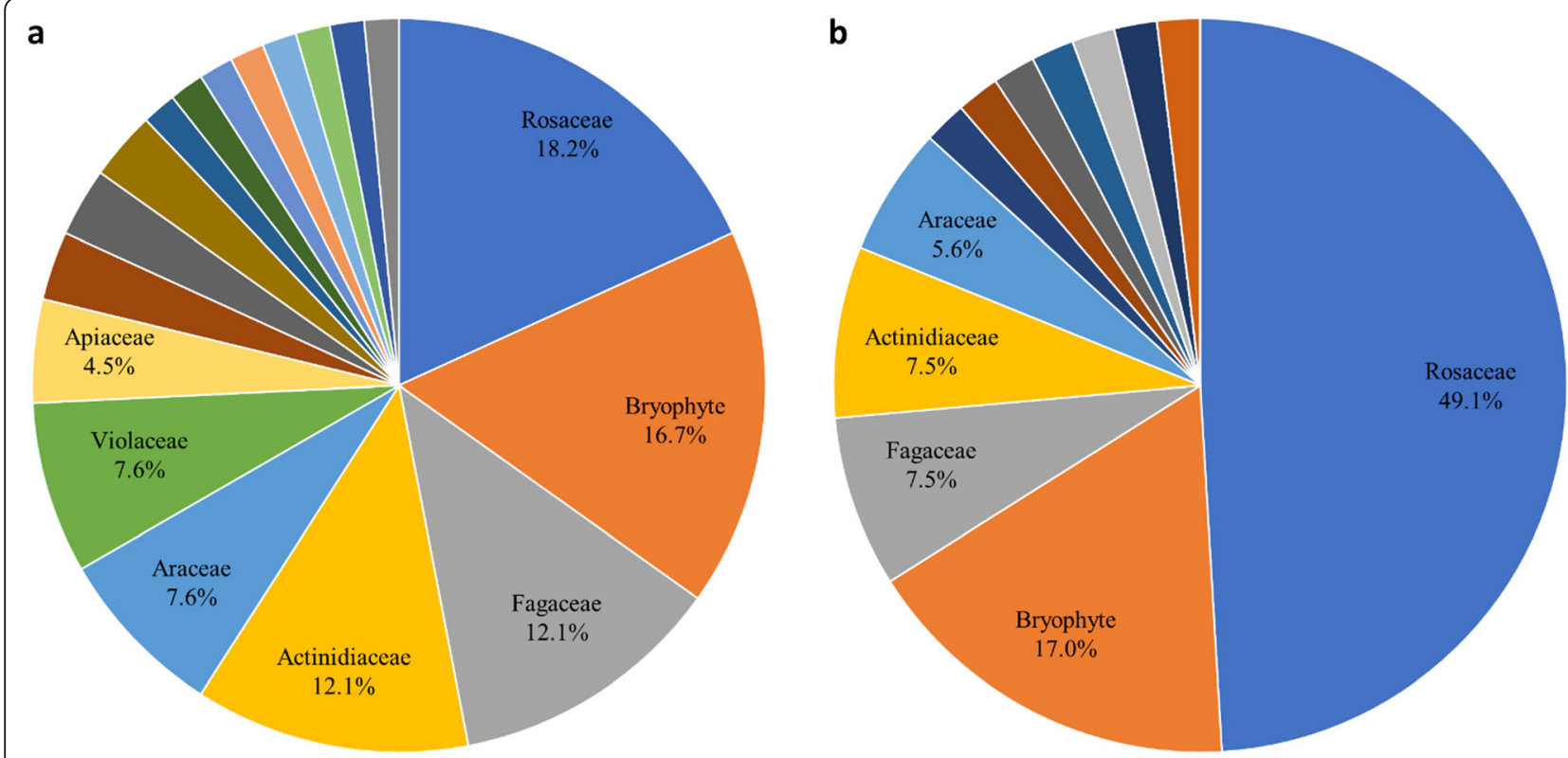

Fig. 3 Comparison of plant food sources detected in wild boar fecal samples during the summer period of 2016 and 2017

Of the 80 total fecal samples collected for this study, 79 samples were successfully amplified in the COI region, and 119 clones of animals were detected as animal food sources (Fig. 4). A total of 12 orders were detected as animal food sources, which were less diverse than were plant food sources. Except for mammals, we had difficulty in identifying these in detail owing to their low resolution. We detected various Insecta belonging to Arthropoda, especially Diptera (flies) and Cleoptera (beetles). Wild boars have a habit of digging the ground

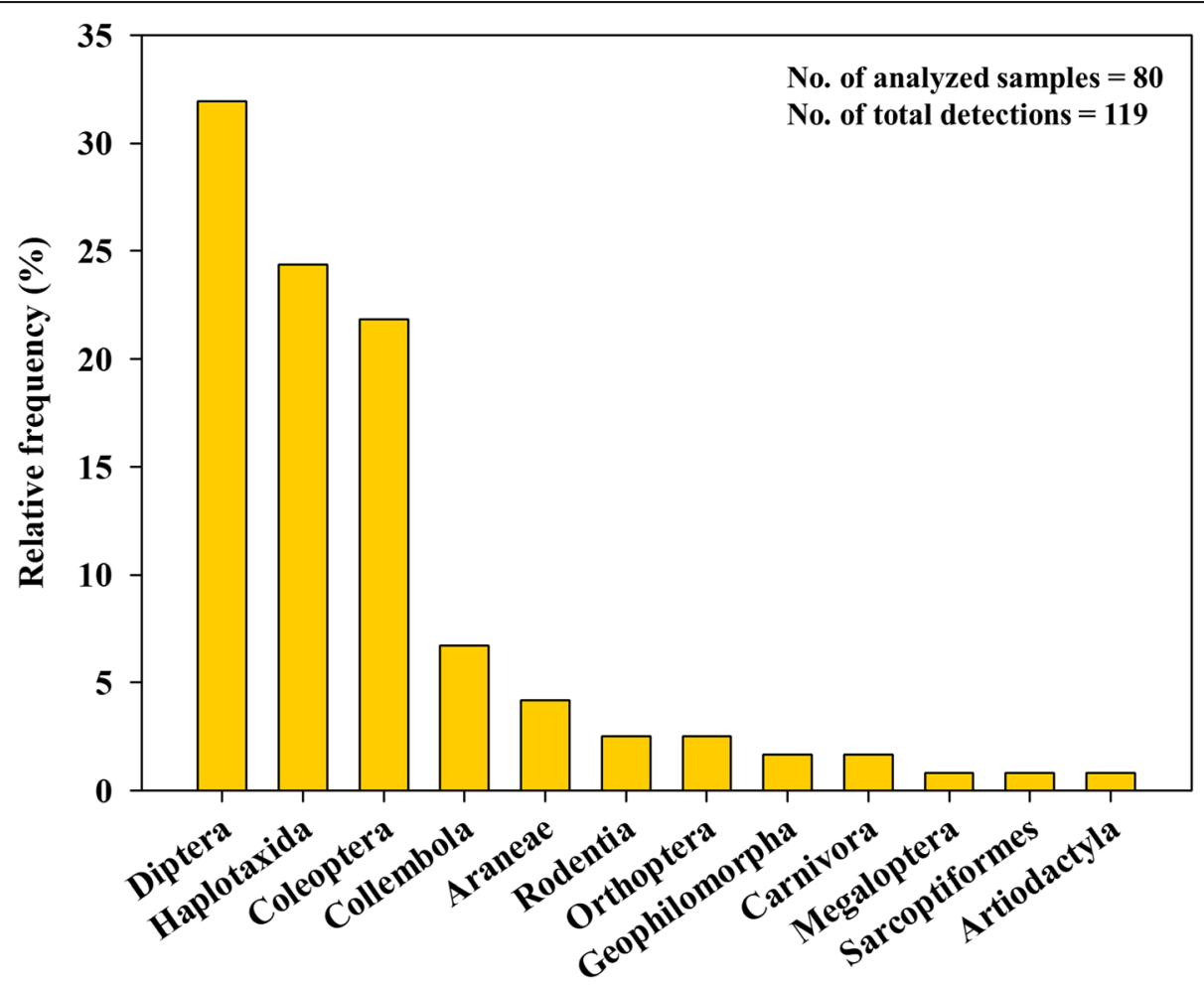

Fig. 4 The percentage of detected animal food sources identified to the order level during the entire study period 
to find food, which likely allows them to eat Diptera larva or Cleoptera larva. In addition, a high proportion of Haplotaxida (earthworms) was detected as animal food sources. Earthworms are widely known as a wild boar food source. From wild boar fecal samples, we detected several mammals known to inhabit the Mt. Jeombongsan area: Rodentia, Carnivora (Meles leucurus [badger]), and Artiodactyla (Naemorhedus caudatus [mountain goat]). These results appear to be instances of opportunistic foraging rather than direct predation or meat eating.

\section{Diet composition by sex}

Of the 80 wild boar fecal samples, 69 were finally determined for their sex. As a result of amplification among the first 80 samples, there were estimated to be 25 males and 35 females. In the case of the sex chromosome $Y$, in some samples, no band was observed in the $Z F$ gene PCR, but only a single band was observed in SRY PCR. In this case, the sample was later reidentified to be a male. Finally, 69 of the total samples were identified and there were estimated to be 34 males and 35 females. The sex ratio of wild boar fecal samples collected from Mt. Jeombongsan was estimated to be approximately 1:1. The relative frequency of each sex is the detected percent based on total plant clones. Male and female wild boars had similar overall tendencies regarding plant food sources (Fig. 5a). Rosaceae, Bryophyte, Fagaceae, and Actinidiaceae were the major plant food sources and occupied more than half of the total. The frequency of Araceae was somewhat high in both sexes. Females consumed various types of plants which were not detected in males. Apiaceae and Cyperaceae were specifically detected in the feces of females. In contrast, Violaceae was only detected in male samples. Male and female wild boars had similar overall tendencies regarding animal food sources (Fig. 5b). Diptera and Coleoptera in Insecta accounted for more than half of the animal food sources of both females and males. Haplotaxida occupied more than a quarter of the animal food source composition of both sexes and were detected to be one of the main animal food sources. Several species of mammals were detected as animal food sources, including small mammals of Rodentia and the relatively large Martes flavigula (Carnivora) and Naemorhedus caudatus (Artiodactyla). Although the proportion of major diet groups was slightly higher in females than in males, there did not appear to be a significant difference.

\section{Diet composition by body size}

In the small body size group, Rosaceae, Bryophyte, and Fagaceae accounted for more than $75 \%$ of the total diet (Fig. 6a). These plants were also detected at a high rate in the large body size group. However, for the large body size group, Actinidiaceae was the most frequently detected plant food source. The three plant food sources with the highest frequencies, Actinidiaceae, Rosaceae and Bryophyte, accounted for more than half of the total diet. The diet compositions of large wild boars were much more diverse than those of small wild boars. Fagaceae was the one of the main plant food sources. Unlike the plant food sources, various animal food sources were also detected in the small body size groups (Fig. 6b). The large body size group showed the highest detection of Diptera and Coleoptera in Insecta. In the small body size group, the detection of Haplotaxida was more frequent than in the large body size group. Mammalian food sources were also more frequently found in the small body size group than in the large body size group.

\section{Discussion}

In this study, we attempted to non-invasively elucidate the diet compositions of Korean wild boar (Sus scrofa coreanus) at Mt. Jeombongsan. Our results were in accordance with previous reports that Korean wild boars are generally omnivores that mainly eat plants, with occasional predation or active hunting (Wilcox and Vuren 2009; Wishart et al. 2015). In addition, our study agrees with a previous report that the diet composition of wild boar depends on accessible food sources (Baubet et al. 2004; Herrero et al. 2006; Barrios-Garcia and Ballari 2012). Body size significantly influences wild boar diet, while sex was not a significant factor.

As a result of the dietary analysis of plant and animal food sources, it appeared that wild boars consumed more diverse plant food sources than animal ones and were more dependent on plant food sources (188 clones of plant food sources vs. 119 clones of animal ones). In the plant clones, 18 orders were identified, while in animal clones, 12 orders were identified. Because of the lack of genetic information on animal food sources, especially for invertebrates, it was not possible to perform a detailed analysis, but the 18 orders of plants compared to the 12 orders of animals indicated that the wild boars ate plants more frequently than animals. Because of the use of different primer sets for plant and animal food source analysis, it was difficult to accurately quantify the relative contributions of plant and animal food sources. However, since the same DNA extracted from 80 feces were used in the experiment and a sufficient number of clones were analyzed, we think that it is reasonable to compare contributions of plant and animal sources. It appeared that wild boars were more dependent on plant food sources than those of animals.

As a result of the dietary analysis of plant food sources, the most commonly detected family was Rosaceae, especially Sanguisorba and Filipendula, which are known to occur in the Mt. Jeombongsan area (KNPRI 2012). Many Bryophyte were detected, but it was not 

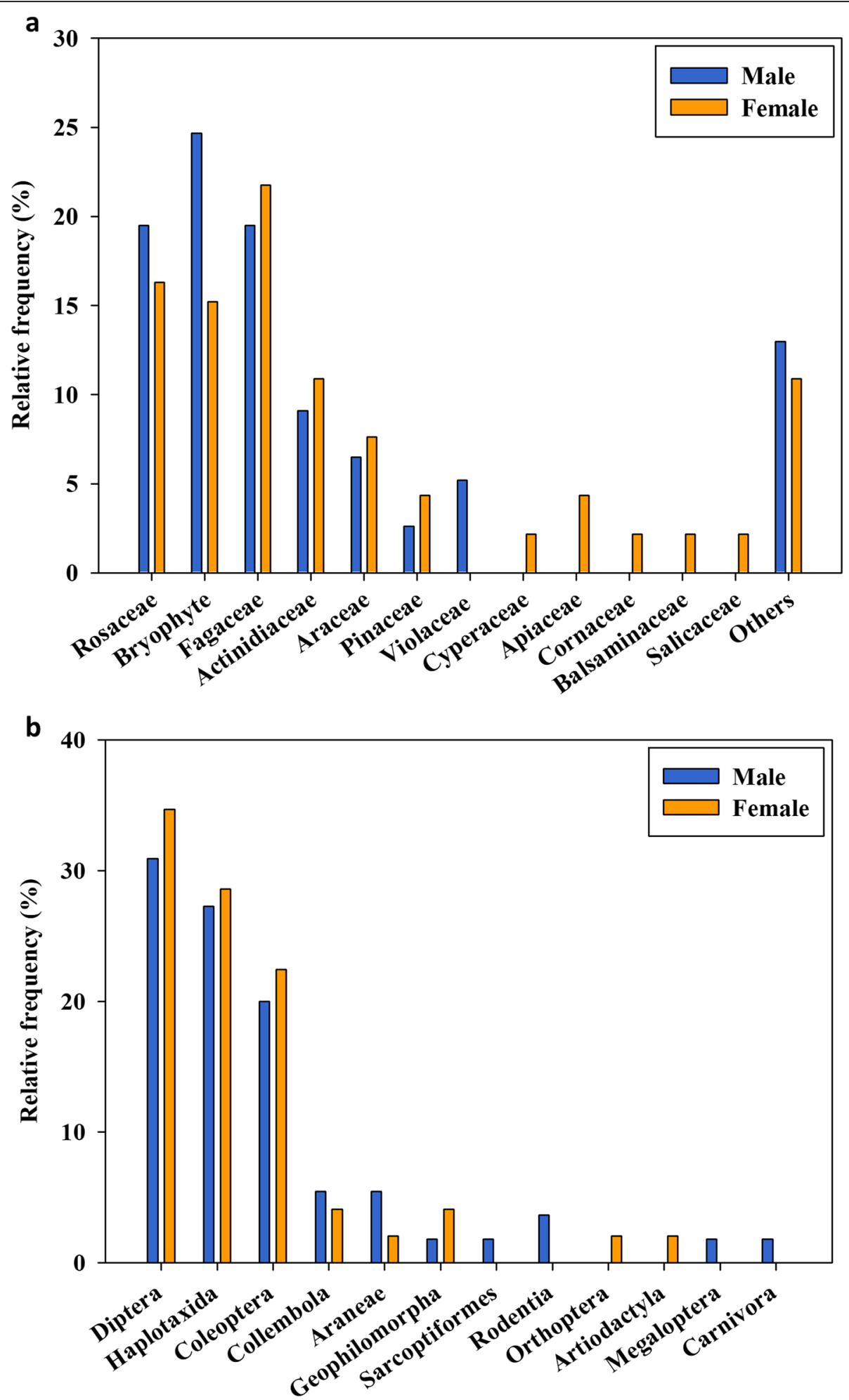

Fig. 5 Differences in food sources detected in the fecal samples of wild boars according to sex (a plant food sources, $\mathbf{b}$ animal food sources)

possible to identify them to the detailed level because of the lack of data in the NCBI database. A recent study reports that wild boars in forest-agricultural areas preferred chestnuts to acorns, but conversely, in urban areas, acorns were consumed more frequently than chestnuts through stomach analysis (Lee and Lee 2019). 

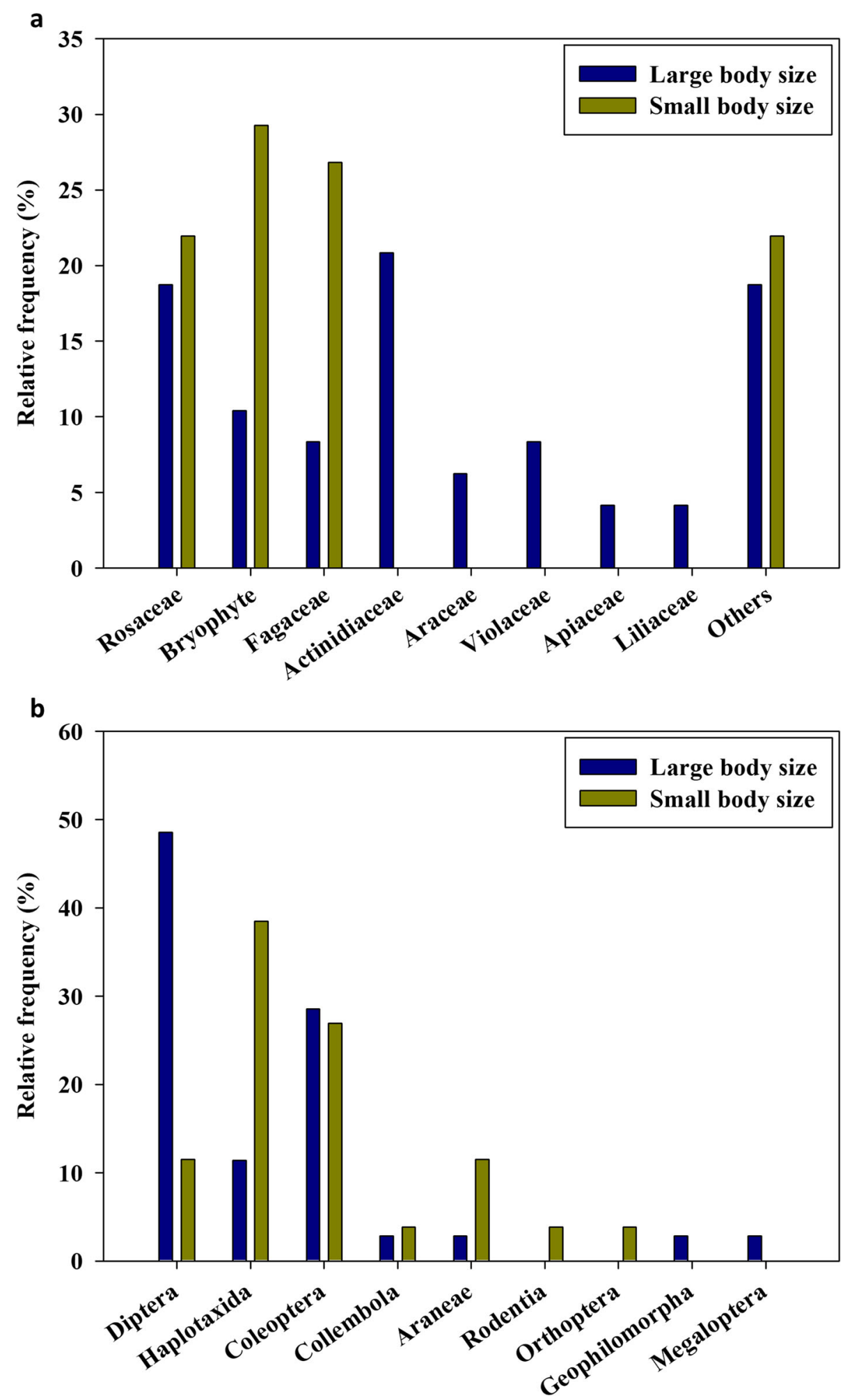

Fig. 6 Differences in food sources detected in fecal samples of wild boars according to body size (a plant food sources, $\mathbf{b}$ animal food sources) 
In addition, Kim et al. (2019) reported that wild boars selectively preferred Quercus forest because acorn is one of the most important food sources for wild boars (Welander 2000; Fonseca 2008). The Fagaceae, which could not be determined which parts of plants, appeared to be important plant food sources for wild boar in Mt. Jeombongsan area as well. The total detected number of nuts of Fagaceae and berries of Actinidiaceae accounted for more than a quarter of the diet composition.

Some researchers suggested the possibility the animal proportions are underestimated in diets because of their high digestibility in scat analysis (Lee and Lee 2019). However, 12 orders of animals were detected in feces, showing more diverse taxa than expected. As a result of the dietary analysis of animal food sources, Diptera and Coleoptera of Insecta were the two most frequently detected animal food sources. Wild boars have a habit of rooting the ground to search for food (KNPRI 2016); they are likely to have eaten larvae or grubs during this behavior. However, it is also possible that they were detected from environmental traces. Haplotaxida, within the annelids, were reported to be the main animal food source for wild boar in a previous report (Baubet et al. 2003). Although DNA of Rodentia was detected, they are not likely usual prey for wild boars because they are very alert and elusive. Moreover, Carnivora and Artiodactyla are relatively large in body size; they are also not likely usual prey for wild boars. It appeared that wild boars at Mt. Jeombongsan area were more opportunistic scavengers rather than aggressive active predators, supported by a previous study showing that vertebrate foods were mostly taken from carrion scavenging behavior of wild boars (Lee and Lee 2019).

As a result of sex determination, the sex ratio of collected fecal samples was almost 1:1, indicating stability. It is possible that the proportion of females was underestimated because the determination of females relied solely on ZF PCR results. The sex ratio can be used not only to show the composition of the current population, but also to show the future potential growth (Kohn and Wayne 1997). However, there is a possibility of resampling the feces of one individual; an accurate sex ratio cannot be estimated without individual identification.

The overall plant food source tendencies between males and females were similar (Fig. 5a). The intake of Rosaceae, Bryophyte, and Fagaceae was more than half in both sexes, and that of Actinidiaceae was also high. Females appeared to have more diverse diets than did males. Apiaceae, commonly used as an herb by humans, appeared to be selectively taken by females and was not detected in male feces. In contrast, Violaceae was only detected in male samples. The tendency of the overall animal food sources between males and females was also similar (Fig. 5b). Diptera, Haplotaxida, and Coleoptera accounted for more than half of the total animal food sources in both sexes. In females, the detection of mammals was slightly higher than that in males, but could not be regarded as significant.

When the results of the food source were classified according to the size of the body, the large and small body size groups showed considerably different diet compositions (Fig. 6). The differences might be because of the difference in the ability to access foods. For plant food sources, the large body size group consumed Actinidiaceae more frequently and Apiaceae exclusively. Small individuals seem to have consumed acorns; they are relatively accessible because they were located at the ground level having fallen from the trees. For animal food sources, more kinds of animal food sources were detected in the small size group than in the large size group. Because the small size group was relatively inefficient at accessing plant food sources compared to the large size group, it appeared that rooting the ground and searching for food was a process to compensate for this.

Studying wild animals non-invasively using feces sampling can provide more detailed and diverse information than can traditional methods (Soininen et al. 2009). In addition, it can be adapted anywhere, such as conserved areas, without any effects on the ecosystem. However, molecular analysis using DNA extracted from fecal samples can cause errors when their qualities are poor. Many inhibitors and contaminants might be mixed together with DNA; it appears that DNA purification and improvement is essential. One limitation of our study was that even if species are detected, it is hard to determine the actual part that was consumed. We think that it is necessary to complement the gut content analysis or complementary comparisons with previous research.

In a further study, it will be necessary to quantify the importance of food sources through measuring how much they have consumed. It would be possible to estimate the structure of the population with sex determination and individual identification (Kolodziej et al. 2012; Kierepka et al. 2016), which might provide valuable information on the wild boar population at Mt. Jeombongsan for management. This non-invasive method can be applied to other animals beyond wild boars and in areas other than Mt. Jeombongsan, helping us to understand the trophic relations and energy flows in these places (Valentini et al. 2008).

\section{Conclusion}

We examined the diet compositions of wild boars in the Mt. Jeombongsan area using fecal sampling. The results showed that wild boars preferred Rosaceae, especially Sanguisorba and Filipendula as plant food sources, and Diptera and Coleoptera of Insecta as animal food sources. It appeared that wild boar chose more 
accessible foods rather than foods that they preferred. Wild boars can be regarded as generalist feeders with a highly flexible diet. Depending on the sex, there was food that was specifically consumed by females as well as by males; however, their overall tendencies were similar. There were differences in the diet composition according to the body size. Our study could help to elucidate the feeding ecology and population structure of wild boars, as well as to address the conservation and management issues.

\section{Abbreviations}

KNPRI: Korean National Park Research Institute; UNESCO: United Nations Educational, Scientific and Cultural Organization

\section{Acknowledgements}

Not applicable.

\section{Authors' contributions}

HMS carried out the field study, performed the analysis, and wrote the manuscript. JK participated in the design of the study, conducted the field studies, and edited the manuscript. SDJ and HYW conceived the study. SP conceived the study and reviewed/edited the manuscript. The authors read and approved the final manuscript.

\section{Funding}

This work was supported by a grant from the National Institute of Ecology (NIE), funded by the Ministry of Environment (MOE) of the Republic of Korea (NIE-B-2020-02).

\section{Availability of data and materials}

The datasets generated and/or analyzed during the current study are available from the corresponding author on reasonable request.

\section{Ethics approval and consent to participate}

Not applicable.

\section{Consent for publication}

Not applicable.

\section{Competing interests}

The authors declare that they have no competing interests.

\section{Author details}

'Department of Biological Science, Ajou University, Suwon 16499, Republic of Korea. ${ }^{2}$ Division of Climate \& Ecology, National Institute of Ecology, Seocheon 33657, Republic of Korea.

Received: 18 February 2020 Accepted: 15 June 2020

Published online: 21 July 2020

\section{References}

Ballari SA, Cuevas MF, Ojeda RA, Navarro JL. Diet of wild boar (Sus scrofa) in a protected area of Argentina: the importance of baiting. Mammal Res. 2015; 60:81-7.

Barrios-Garcia MN, Ballari SA. Impact of wild boar (Sus scrofa) in its introduced and native range: a review. Biol Invasions. 2012;14(11):2283300.

Baubet E, Ropert-Coudert Y, Brandt S. Seasonal and annual variations in earthworm consumption by wild boar (Sus scrofa scrofa L.). Wildl Res. 2003; 30(2):179-86

Baubet $\mathrm{E}$, Bonenfant $\mathrm{C}$, Brandt $\mathrm{S}$. Diet of the wild boar in the French alps. Galemys. 2004;16:101-13.

Calenge C, Maillard D, Fournier P, Fouque C. Efficiency of spreading maize in the garrigues to reduce wild boar (Sus scrofa) damage to Mediterranean vineyards. Eur J Wildl Res. 2004;50(3):112-20.

Carr CM, Hardy SM, Brown TM, Macdonald TA, Hebert PD. 2011. A trioceanic perspective: DNA barcoding reveals geographic structure and cryptic diversity in Canadian Polychaetes. PLoS One, 2011;6(7): e22232.

Cho IC, Kang SY, Lee SS, Choi YL, Ko MS, Oh MY, Han SH. Molecular sexing using SRY and ZF genes in pigs. J Anim Sci Technol. 2005;47(3):317-24 (in Korean).

Choi TY, Lee YS, Park CH. Home-range of wild boar, Sus scrofa, living in the Jirisan National Park, Korea. J Ecol Environ. 2006;29(3):253-7 (in Korean).

Fonseca C. Winter habitat selection by wild boar Sus scrofa in southeastern Poland. Eur J Wildl Res. 2008:54(2):361-6.

Han SH, Oh JG, Cho IC, Ko MS, Kim TW, Chang MH, Kim BS, Park SG, Oh HS. A molecular genetic analysis of the introduced wild boar species (Sus scrofa coreanus) on Mount Halla, Jeju Island, Korea. J Ecol Environ. 2011;25(5):65865 (in Korean).

Herrero J, Garcia-Serrano A, Couto S, Ortuño VM, García-González R. 2006. Diet of wild boar Sus scrofa L. and crop damage in an intensive agroecosystem. Eur J Wildl Res 2006;52(4):245-250.

Kierepka EM, Unger SD, Keiter DA, Beasley JC, Rhodes JROE, Cunningham FL, Piaggio AJ. Identification of robust microsatellite markers for wild pig fecal DNA. J Wildl Manag. 2016;80(6):1120-8.

Kim Y, Cho S, Choung Y. Habitat preference of wild boar (Sus scrofa) for feeding in cool-temperate forests. J Ecol Environ. 2019;43(1):30.

KNPRI. Seoraksan National Park Resource Investigation - Jeombongsan. Korea National Park Research Institute: Namwon; 2012. (in Korean).

KNPRI. A survey of the distribution of Sus scrofa in urban national parks. Korea National Park Research Institute: Wonju; 2016. (in Korean).

Kohn MH, Wayne RK. Facts from feces revisited. Trends Ecol Evol. 1997;12(6):223-7.

Kolodziej K, Theissinger K, Brün J, Schulz HK, Schulz R. Determination of the minimum number of microsatellite markers for individual genotyping in wild boar (Sus scrofa) using a test with close relatives. Eur J Wildl Res. 2012;58(3): 621-8.

Kress WJ, Erickson DL. A two-locus global DNA barcode for land plants: the coding $\mathrm{rbcL}$ gene complements the non-coding trnH-psbA spacer region. PLoS One. 2007:2(6):e508.

Lee SM, Lee WS. Diet of the wild boar (Sus scrofa) in Agricultural Land of Geochang, Gyeongnam Province, Korea. Jour Korean For Soc. 2014;103(2):307-12.

Lee SM, Lee EJ. Diet of the wild boar (Sus scrofa): implications for management in forest-agricultural and urban environments in South Korea. Peer J. 2019;7: e7835.

Leray M, Yang JY, Meyer CP, Mills SC, Agudelo N, Ranwez V, Boehm JT, Machida RJ. A new versatile primer set targeting short fragment of the mitochondrial $\mathrm{COl}$ region for metabarcoding metazoan diversity: application for characterizing coral reef fish gut contents. Front Zool. 2013;10(1):34.

Morden CJC, Weladjia RB, Ropstad E, Dahl E, Holand Ø. Use of faecal pellet size to differentiate age classes in female Svalbard reindeer Rangifer tarandus platyrhynchus. Wildl Biol. 2011:17(4):441-8.

Riaz T, Shehzad W, Viari A, Pompanon F, Taberlet P, Coissac E. ecoPrimers: inference of new DNA barcode markers from whole genome sequence analysis. Nucleic Acids Res. 2011;39(21):e145.

Robeson MS, Khanipov K, Golovko G, Wisely SM, White MD, Bodenchuck M, Smyser TJ, Fofanov Y, Fierer N, Piaggio AJ. Assessing the utility of metabarcoding for diet analyses of the omnivorous wild pig (Sus scrofa). Ecol Evol. 2018;8(1):185-96.

Skogland T. Sex ratio in relation to maternal condition and parental investment in wild reindeer Rangifer t. tarandus. Oikos. 1986:46(3):417-9.

Soininen EM, Valentini A, Coissac E, Miquel C, Gielly L, Brochmann C, Brysting AK, Sønstebø JH, Ims RA, Yoccoz NG, Taberlet P. Analysing diet of small herbivores: the efficiency of DNA barcoding coupled with high-throughput pyrosequencing for deciphering the composition of complex plant mixtures. Front Zool. 2009;6(1):16.

Taberlet P, Coissac E, Pompanon F, Gielly L, Miquel C, Valentini A, Vermat T, Corthier G, Brochmann C, Willerslev E. Power and limitations of the chloroplast trnL (UAA) intron for plant DNA barcoding. Nucleic Acids Res. 2007:35(3):e14.

Valentini A, Pompanon F, Taberlet P. DNA barcoding for ecologists. Trends Ecol Evol. 2008:24(2):110-7.

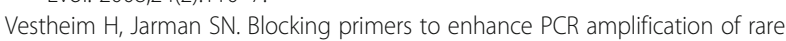
sequences in mixed samples - a case study on prey DNA in Antarctic krill stomachs. Front Zool. 2008:5(1):12.

Welander J. Spatial and temporal dynamics of wild boar (Sus scrofa) rooting in a mosaic landscape. J Zool. 2000;252(2):263-71.

Wilcox JT, Vuren DH. Wild pigs as predators in Oak Woodlands of California. J Mammal. 2009;90(1):114-8. 
Wirthner S, Schutz M, Page-Dumroese DS, Busse MD, Kirchner JW, Risch AC. Do changes in soil properties after rooting by wild boars (Sus scrofa) affect understory vegetation in Swiss hardwood forests? Can J For Res. 2012;42(3): 585-92.

Wishart J, Lapidge S, Braysher M, Sarre SD, Hone J. Observations on effects of feral pig (Sus scrofa) age and sex on diet. Wildl Res. 2015;42(6):470-4.

\section{Publisher's Note}

Springer Nature remains neutral with regard to jurisdictional claims in published maps and institutional affiliations.

- fast, convenient online submission

- thorough peer review by experienced researchers in your field

- rapid publication on acceptance

- support for research data, including large and complex data types

- gold Open Access which fosters wider collaboration and increased citations

- maximum visibility for your research: over $100 \mathrm{M}$ website views per year

At $\mathrm{BMC}$, research is always in progress. 